\title{
PERCEPÇÕES E ATITUDES DE RESIDENTES EM RELAÇÃo ÀS ÁRVORES URBANAS DE PALMAS-TO
}

\author{
Marcleiton Ribeiro Morais ${ }^{1}$; Adriano Firmino V. de Araújo; Erika Cristine Kneib ${ }^{3}$
}

(recebido em 21.01.2011 e aceito para publicação em 15.09.2011)

\section{RESUMO}

A criação de Palmas/TO foi marcada por um discurso modernista que buscava unir no mesmo lugar condições para seus residentes habitar, trabalhar e recrear-se tudo isso em consonância com os paradigmas ecológicos da época. Todavia, a jovem cidade tem sofrido com a subprovisão dos serviços da vegetação arbórea. Assim, a questão básica desse estudo é avaliar a percepção dos moradores de Palmas em relação a sua vegetação arbórea, identificando atitudes e conhecimentos no tocante as suas árvores urbanas. Foram entrevistados 410 indivíduos a partir de uma amostra probabilística por conglomerado dada em múltiplos estágios. Envolvendo questões de ordem socioeconômicas, questões a respeito do meio ambiente e do ativo analisado. Os resultados comprovam uma expectativa a priori de que a percepção e ações de seus residentes conferem certa divergência entre o panorama atual da cobertura arbórea urbana e o discurso ecologicamente correto que por muito tempo foi difundido no município. No que tange às atitudes, a significativa proporção de indivíduos integrativos revela em escala de grandeza à escolha social quanto à necessidade de disposição de árvores no recinto da cidade.

Palavras-chave: Conduta; Cobertura arbórea urbana; Planejamento urbano.

\footnotetext{
1. Economista Mestre em Desenvolvimento Regional e Agronegócio; Professor Assistente da Universidade Federal do Tocantins; Campus de Palmas-TO. mrm@uft.edu.br.

2. Doutor em Economia; Economista; Professor Adjunto da Universidade Federal do Tocantins - UFT vinculado ao Programa de Mestrado em Desenvolvimento Regional e Agronegócio. Campus de Palmas-TO. Affva77@uft.edu.br.

${ }^{3}$.Arquiteta Doutora em Transportes pela Universidade de Brasília; Professora Adjunta da Universidade Federal de Goiás. Campus de Goiânia-GO. erikakneib@terra.com.br.
} 


\section{VIEWS AND ATTITUDES OF RESIDENTS TOWARDS URBAN TREES OF PALMAS-TO}

\section{ABSTRACT}

The creation of Palmas/TO was marked by a modernist discourse looking forward to bringing together the resident's living,working and recreational conditions in line with the ecological paradigms at that time. However, the new city has gone through an underprovision of services for woody vegetation. So, this study is basically aimed at assessing the views of Palmas residents on its woody vegetation, identifying attitudes and knowledge of urban trees. As 410 people were interviewed using the multistage cluster sampling method, the study included socioeconomic as well as environmental issues. The results a priori prove that the views and attitudes of Palmas residents show a divergence between the current panorama of the urban tree canopy and the ecologically correct speech that was broadcast in the municipality for a long time. When it comes to attitudes, the significant proportion of integrative individuals reveals in a large scale the social choice regarding the need of tree dispositions in the city.

Key-words: Conduct; Urban tree canopy; urban planning.

\section{INTRODUÇÃO}

A promulgação da Carta Magna brasileira em 1988, Brasil (1988), marca o passo inicial para o estabelecimento da nova visão internacional sobre a composição do recinto das cidades no país, que deveria integrar em proporção adequada aos elementos artificializados e os ambientais, sobretudo a vegetação arbórea. Isso porque as árvores proporcionam benefícios como: a purificação do ar; a melhoria do microclima, proteção quanto à incidência de raios solares; redução da velocidade do vento; evaporação mais lenta; abrigo à fauna, propiciando uma variedade maior de espécies, e consequente maior equilíbrio das cadeias alimentares e diminuição de pragas e agentes vetores de doenças; amortecimento de ruído; ação sobre o bem estar físico e psíquico do homem; emissão de

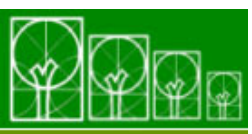

$\mathbf{S} \cdot \mathbf{B} \cdot \mathbf{A} \cdot \mathbf{U}$ Soc. Bras. de Arborização Urbana 
fragrância agradável, além de refrescar o ambiente e suavização do aspecto visual em contraste com as edificações, entre outros (GREY; DENEKE, 1978; MASCARÓ; MASCARÓ, 2005, MILANO; DALCIN, 2000; WOLF, 2004).

Foi objetivando integrar tais benefícios que a capital do Estado de Tocantins, Palmas, foi criada. Vasconcellos (2006) afirma que a cidade está entre as poucas capitais brasileiras centradas na concepção contemporânea. Seu modelo modernista dispunha de condições favoráveis para integrar novos parâmetros de qualidade ambiental para não replicar os processos de degradação ambiental observados em outras cidades brasileiras (XAVIER, 2007). O principal desafio seria combinar seu discurso progressista e empresarial com os reclames da moderna sustentabilidade ambiental para a construção de uma real política urbana que privilegie a gestão, a planificação e o desenvolvimento centrados no homem (BERTONE; MELLO, 2004). Assim, a cidade que deveria conter o paço dos três poderes estadual e servir como elo de integração dos demais municípios emergiu cercada de expectativas e obrigações.

Entretanto, a expansão urbana vertiginosa da década de 1990 desfavoreceu a ocupação parcelada do território previsto no Plano Diretor Urbanístico. Processo agravado com a deliberação de políticas de segregação social, que produziu impactos negativos nos custos de fornecimento de serviços urbanos, comprometendo a quantidade e qualidade dos mesmos, dentre eles os serviços ambientais. Seus atenuantes climáticos como os altos índices de temperatura, a baixa umidade do ar, a poluição atmosférica; em virtude da forte incidência de vento sobre um cerrado descoberto, haja vista a ausência expressiva de vegetação nos passeios públicos, nos canteiros centrais, nas praças e espaços de convívio (PALMAS, 2006); têm produzido significativo desconforto ambiental e, assim, perda da qualidade de vida de seus habitantes. Nascimento Júnior (2006) afirma que esse processo fez com que contrastes e desigualdades sociais se tornassem nítidos na paisagem da cidade.

Ao longo de sua implantação, observou-se forte degradação da vegetação arbórea via desmatamento da vegetação nativa das Áreas de Proteção Ambiental, de modo que grande parte de suas áreas naturais foi suprimida. Segundo Fighera (2005), as preocupações iniciais de caráter ambiental não foram respondidas nas ações que se sucederam em sequência à implantação. Esses problemas se agravam devido à ausência de planejamento adequado da vegetação arbórea urbana, bem como devido má gestão, uso e ocupação do solo. Mesmo dispondo de um plano diretor definido, a cidade não possui um planejamento para a sua adequada arborização. Dessa forma, o tecido urbano da cidade

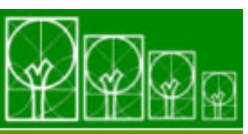

$\mathbf{S} \cdot \mathbf{B} \cdot \mathbf{A} \cdot \mathbf{U}$ Soc. Bras. de Arborização Urbana 
comporta inúmeras iniciativas paisagísticas de diversos governos municipais, o que the impôs prejuízos atuais e futuros.

Paradoxalmente, o município tem sido citado nacionalmente como sendo uma cidade com ampla disposição de espaços verdes. Esse discurso coaduna com a máxima de que a preservação dessa vegetação desempenha funções socioambientais e econômicas importantíssimas para o convívio harmonioso do homem urbano (GREY; DENEKE, 1978). Nesse sentido, cabe uma reflexão: a visão paisagística do município baseada no ufanismo do seu ideal urbanístico - marketing como atrativo turístico que o slogan "capital ecológica" representou por vários anos (LIRA, 1995) - estabelece uma real apropriação de benefícios perceptíveis nas ações de seus residentes?

Melazo (2005) argumenta que a percepção ambiental deve ser entendida enquanto um processo participativo, envolvendo uma série de fatores sensoriais, subjetivos e valores sociais, culturais e atitudes ambientais das comunidades residentes. Assim, o estudo da percepção centrado na investigação e compreensão dos sentimentos e valores têm um papel importante para formação de juízos de valor e atitudes que orientam ações sobre estes espaços (COSTA; COLESANTI, 2011). Faggionato (2007) esclarece que saber como os indivíduos percebem o ambiente em que estão inseridos, suas fontes de satisfação e insatisfação é de fundamental importância para que se possa compreender melhor suas expectativas, julgamentos e condutas.

Portanto, o objetivo desse estudo é analisar a percepção dos moradores do Plano Diretor de Palmas/TO em relação a sua vegetação arbórea, confrontando atitudes e conhecimentos no tocante ao discurso de "capital ecologicamente correta", como requisito da apropriação de possíveis benefícios.

\section{MATERIAIS E MÉTODOS}

\section{Caracterização da Área de Estudo}

Localizado no Planalto Central Brasileiro, o sítio urbano escolhido para receber a cidade de Palmas apresentava forte identidade paisagística (PALMAS, 2006). Seu perímetro urbano compreende 2.218,934 km² situados entre os ribeirões Água Fria e Taquaruçú Grande posicionados entre a margem direita do rio Tocantins e a serra do Lajeado, próximo ao antigo povoado de Canela, conforme Figura 1. O município tem como fronteira os

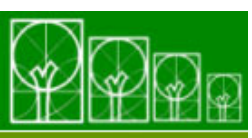

$\mathbf{S} \cdot \mathbf{B} \cdot \mathbf{A} \cdot \mathbf{U}$ Soc. Bras. de Arborização Urbana 
municípios de Aparecida do Rio Negro, Novo Acordo, Lajeado e Miracema do Tocantins a Norte; ao Sul, Monte do Carmo e Porto Nacional; a Leste, Santa Tereza do Tocantins e Novo Acordo; a Oeste, Porto Nacional e Miracema do Tocantins (PALMAS, 2002).

Figura 1. Localização do sítio urbano da cidade de Palmas

Figure 1. Location of the urban area in Palmas.

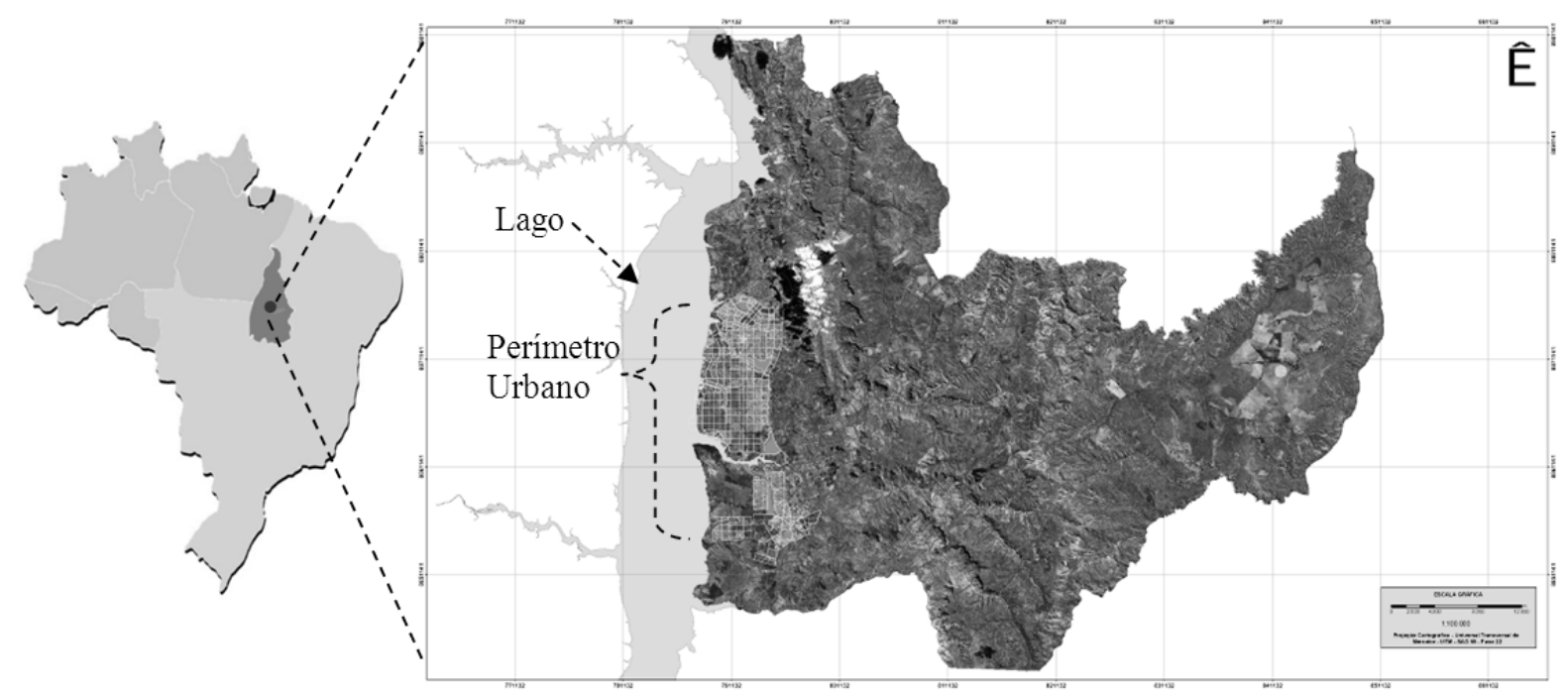

O espaço é de domínio dos Cerrados, região com aspecto vegetal preponderante do tipo savana arbórea aberta com floresta de galeria correspondente ao relevo da depressão do Rio Tocantins. Sua vegetação sofre modificações estacionais; na estação seca, a paisagem dá uma nota de angústia pelo retorcido dos caules e dos galhos mais ou menos desnudados; na estação chuvosa, observa-se um aceleramento na vida vegetal: a folhagem adensa-se e pintalga-se de flores, que muitas vezes precedem ao aparecimento das folhas (FERREIRA, 2005).

As principais espécies arbóreas que compõem a cobertura vegetal predominante na área são: pequizeiro (Caryocar brasiliense); pau-terra-de-folha-larga (Qualea grandiflora); pau-terra (Qualea parviflora); vinhático (Platymenia reticulata); Barbatimão (Stryphnodendron adstringens); Faveira (Dimorphandra mollis); Goiabeira-do-campo (Myrcia sp.); Murici (Byrsonima spp.) Pitanga (Eugenia sp.); Cajueiro (Anacardium sp.); entre outras (SEPLAN, 2004). 
Figura 2. Paisagem fitoecológica do sítio urbano da cidade de Palmas/TO

Figure 2. Phyto-ecological landscape in the urban area of Palmas/TO

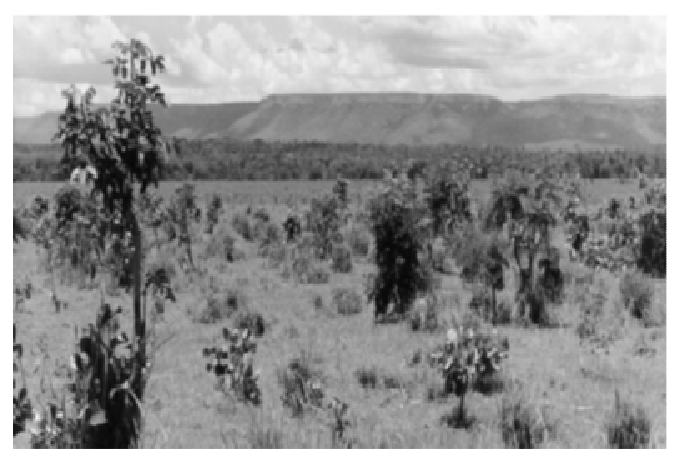

Todavia, a intensa urbanização sofrida pela cidade trouxe consigo as práticas de queimadas e o uso do solo sem primar pela conservação, o que produziu expressiva modificação aos seus aspectos naturais. Fighera (2005) preconiza que o processo de urbanização foi marcado pelo processo de "terras arrasadas", através da retirada da cobertura natural nativa. Constituiu-se um mosaico na paisagem arbórea do município. Ora priorizou-se o plantio de uma vegetação estritamente exótica aclimatada de outras regiões, em substituição à nativa e com ampla exposição do tecido urbano à insolação, - foram plantados exemplares da Palmeira Imperial (Roystonea oleracea) - ora foram empregadas monoculturas - a cidade apresenta aproximadamente cinco espécies arbóreas que são utilizadas na arborização, dentre elas o jambolão (Eugenia jambolana) e o oiti (Licania tomentosa) - o que torna preocupante pela possibilidade de ocorrência de pragas, as quais dizimariam grande parte da vegetação da cidade (PALMAS, 2006).

Seu clima é considerado tropical quente e úmido, com duas estações bem definidas, uma seca e outra chuvosa (úmida). O caráter cíclico de suas estações o caracteriza com uma homogeneidade climática com situações excepcionais de grandes tempestades, períodos extensos de seca fora da época, ventos de grande velocidade e predominantes no período final das secas. Apresenta temperatura média de $25,6^{\circ} \mathrm{C}$; atingindo máximas de $41^{\circ} \mathrm{C}$ com sensação térmica em torno dos $46^{\circ} \mathrm{C}$ ao final do inverno (UNITINS, 2010).

\section{Fonte de Dados e Procedimentos}

Os dados utilizados são essencialmente primários coletados diretamente da população a partir da aplicação de questionários semi-estruturados, já que desde o início

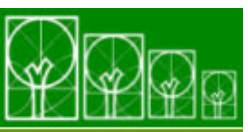

$\mathbf{S} \cdot \mathbf{B} \cdot \mathbf{A} \cdot \mathbf{U}$ Soc. Bras. de Arborização Urbana 
foram realizadas adaptações dos mesmos para que os objetivos do estudo fossem atendidos. O universo de investigação corresponde a uma amostra probabilística por conglomerado dada em múltiplos estágios compreendendo 410 entrevistas.

O instrumento de coleta contempla questões de ordem sócio-econômicas e questões específicas a respeito do meio ambiente e do ativo analisado, contendo um total de 21 perguntas. As oito primeiras questões objetivam captar do entrevistado seu status sócioeconômico, envolvendo atributos como: sexo, idade, escolaridade, ocupação, renda individual e familiar, quantidade anos que reside em Palmas - TO, entre outros. A partir da nona questão busca-se introduzir a problemática ambiental bem como avaliar a afinidade do entrevistado com a mesma, em especial com relação aos elementos arbóreos urbanos e sua interação com o recinto das cidades.

Cabe destacar que na questão onze foi proposto agrupar os entrevistados com base em uma escala de atitude em relação à vegetação arbórea urbana, construída por Gold (1977) e testada semanticamente por Alves e Gouveia (1995). Nesta escala, os indivíduos são agrupados com base em três tipos de atitudes: atitudes integrativas, ambivalentes e escapistas. Na primeira categoria, as árvores são vistas como elementos essenciais para o planejamento do ambiente urbano; enquanto para indivíduos ambivalentes estas são meras atrações, sendo dispensáveis para as necessidades culturais e funcionais das cidades. Já nas atitudes consideradas escapistas o homem tenta recriar o ambiente do campo na cidade, ou seja, duplicar a natureza em símbolos (jardins, plantas de vaso), dentro do próprio ambiente.

As perguntas a partir da décima quinta investigam a percepção do entrevistado a respeito das condições atuais da vegetação arbórea de Palmas - TO. Entre outros propósitos, buscou-se captar a percepção do entrevistado com relação à questão das árvores no município sob três âmbitos: a cidade, a quadra e rua. A idéia é investigar se a grande ênfase dada ao tema na cidade em detrimentos de suas problemáticas, sobretudo a concentração desses serviços, produz diferentes avaliações. Nesse sentido, a questão de número dezoito traz uma avaliação detalhada da eficiência da cobertura arbórea da rua do entrevisto. Para isso, foi utilizada uma Escala Likert numerada de 1 a 5. A Escala Likert é um tipo de escala de resposta psicométrica usada comumente em questionários, é a escala mais usada em pesquisas de opinião. Ao responderem a um questionário baseado nesta escala, os perguntados especificam seu nível de concordância com uma afirmação (ELEJABARRIETA; INIGUEZ, 1984). O objetivo é avaliar o nível de concordância do entrevistado sobre um determinado atributo avaliado.

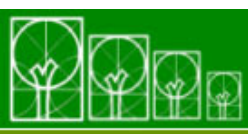

$\mathbf{S} \cdot \mathbf{B} \cdot \mathbf{A} \cdot \mathbf{U}$ Soc. Bras. de Arborização Urbana 


\section{RESULTADOS E DISCUSSÕES}

As entrevistas compõem-se de $46,59 \%$ de indivíduos do sexo feminino e $53,41 \%$ do sexo masculinos com uma média de idade em torno de 35 anos. Quanto á escolaridade, a amostra apresentou uma média de 11,01 anos de estudo, com entrevistado sem instrução alguma em contrapartida ao grau de pós-graduação de outros. Em média, os entrevistados residem na capital do estado há aproximadamente 8,4 anos. Em relação ao setor de trabalho; $36,5 \%$ deles atuam na iniciativa privada; $25,1 \%$ são funcionários públicos; $21,7 \%$ trabalham no setor informal em atividades autônomas; o total de desempregados é de $10,7 \%$; aposentados e pensionistas em torno de $4 \%$ e empregadores com $1,9 \%$. Tendo como base o conceito de desemprego aberto, a taxa de desocupados seria de cerca de $12 \%$ com um ônus demográfico dado pela população de aposentados e pensionistas.

Quanto à caracterização do orçamento familiar, a renda média individual foi de $\mathrm{R} \$ 1.287,44$ pouco mais da metade da renda familiar $(\mathrm{R} \$ 2.786,81)$. Considerando o número de dependentes de 3,2; a renda familiar per capita corresponde a $\mathrm{R} \$ 870,87$. A maior proporção de indivíduos com renda até três salários mínimos estão nas regiões Noroeste $(44,52 \%)$ e Nordeste $(40,51 \%)$ do Plano Diretor enquanto que os maiores níveis de renda estão nas regiões Sudoeste e Sudeste. Naquelas regiões, a população de baixa renda foi atraída com a acelerada e irregular urbanização do início da ocupação da cidade.

Em geral, a proximidade do centro administrativo estabelece um indicativo do padrão de renda mais elevado tanto no sentido Leste-Oeste (Avenida JK) quanto no Norte-Sul. Essa centralidade revela um paralelismo do fator renda com o padrão de acesso aos serviços da vegetação arbórea urbana, os quais estão centralizados nas proximidades dessas vias arteriais.

A Figura 3 apresenta percepções e atitudes dos entrevistados no que tange à questão ambiental e especificamente às árvores urbanas. Quanto a este considerar-se interessado pela questão ambiental (Figura 3a), pouco mais da metade assumiu ter um alto grau de interesse. Acrescendo a estes resultados os indivíduos que declararam ter um nível de interesse médio, somam-se cerca de $92 \%$ dos entrevistados, sendo que o restante, quase $8 \%$, estão os entrevistados com nível baixo ou nenhum. Dessa forma, poder-se-ia estabelecer conclusivamente pela forte presença de interesse ambiental pelo ativo, fator que pode ser mais bem avaliado mediante a interação com as atitudes do entrevistado frente ao ativo.

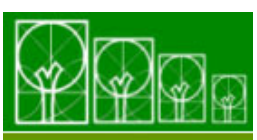

$\mathbf{S} \cdot \mathbf{B} \cdot \mathbf{A} \cdot \mathbf{U}$ Soc. Bras. de Arborização Urbana 
Foi avaliado ainda o grau de importância que esses atribuíam à disposição de cobertura arbórea nos centros citadinos (Figura 3b), em que os entrevistados declararam ser conscientes de que tais elementos urbanos desempenham um papel ímpar para o equilíbrio desses ambientes. Nesse caso, os argüidos que atribuem alta importância ou média somam-se em torno de $97 \%$ dos entrevistados. Os $3 \%$ restantes responderam como sendo baixa tal importância. Essa importância dada às árvores também será confrontada com as atitudes do entrevistado.

Outro aspecto relevante para traduzir tal importância trata-se da percepção dos indivíduos do incômodo gerado pela falta da vegetação arbórea (Figura 3c). Quanto a isso, os entrevistados também são praticamente unânimes de que há algum tipo de incômodo gerado devido a má disposição ou a falta desse tipo de ativo ambiental. Apenas 2,2\% argumentam não haver algum tipo de incômodo.

Ademais, os entrevistados foram agrupados no que tange ao tipo de atitude em relação ao ativo (Figura $3 d$ ). Nesse caso, 68,29\% apresentaram atitude integrativa seguidos de $20,49 \%$ com atitude escapista e $11,22 \%$ ambivalentes. Relativo a isso, em se tratando de como quase metade da amostra contribui com vegetação arbórea urbana, 60,7\% afirmam não danificar as árvores plantadas, seguidos de 21,9\% participam ativamente plantando árvores e 17,4\% afirmam realizar manutenções como poda e irrigação. 
Figura 3. Composição da amostra quanto ao nível de interesse por questões ambientais, grau de importância atribuída à vegetação arbórea urbana, o incômodo associado a não disposição desse ativo e a atitude do entrevistado.

Figure 3: Composition of the sample according to the level of interest in environmental issues, degree of importance given to the urban woody vegetation, inconvenience associated with the non-disposition of it, and interviewee's attitude.

Interesse

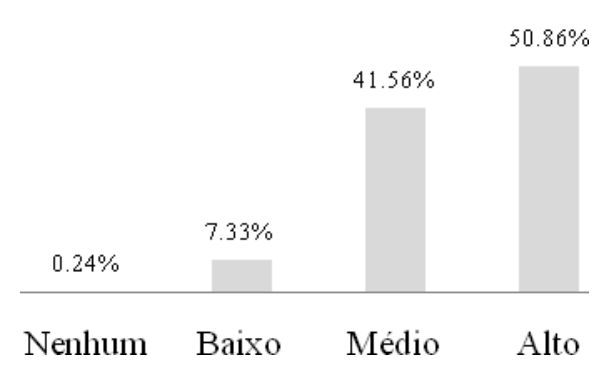

(a)

Incômodo

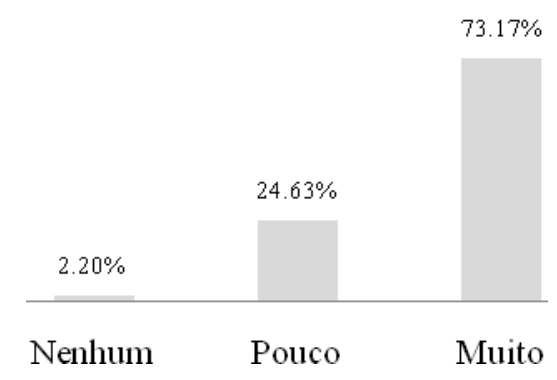

(c)

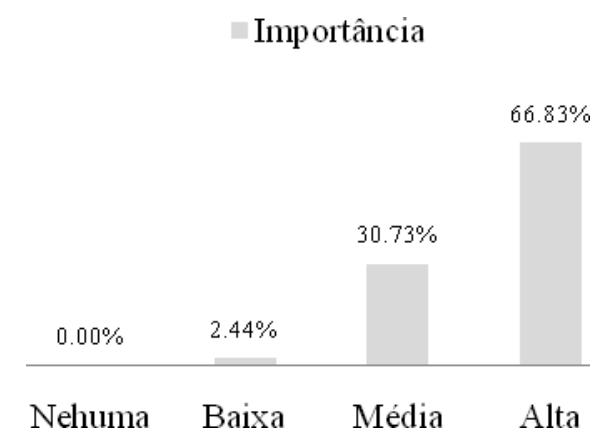

(b)

Atitude

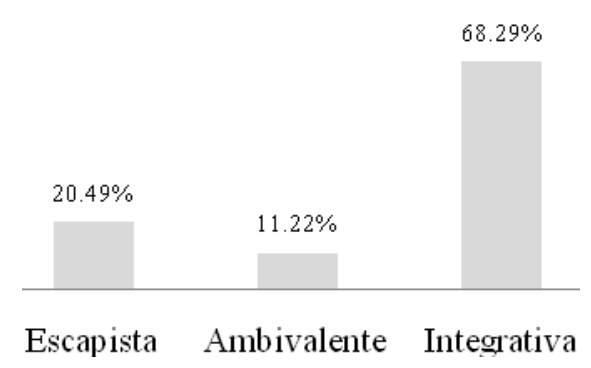

(d)

Contraditoriamente, mais da metade $(51,4 \%)$ do total de entrevistados com alto interesse não contribuem de nenhuma forma para a arborização do bairro. No que se refere ao nível de interesse, tal resultado pode ser decorrente do comportamento estratégico do entrevistado frente ao entrevistador. Quando o nível de interesse é médio essa estimativa cai para cerca de $45 \%$. Já com um nível baixo, mas de dois terços também não contribuem com vegetação arbórea. A relação nível de interesse e percepção de incômodos gerados é positiva, ou seja, quanto maior o nível de interesse maior a percepção do entrevistado quanto aos incômodos gerados. Esse resultado fornece um indicativo de comportamento plausível do indivíduo ao revelar uma estreita relação do envolvimento do mesmo com a 
questão como mecanismos para sua percepção dos benefícios e problemas relativos a essa vegetação.

Resultado semelhante foi obtido ao se contrapor interesse e atitudes bem como interesse e importância dada ao ativo. Os entrevistados com atitudes integrativas são em sua maioria os entrevistados que apresentam maior nível de interesse, seguidos por pessoas escapistas que ainda assim consideram-se preocupadas com as questões ambientais, como uma diferença gradual à medida que estes últimos tendem a apresentar um interesse médio, o que é esperado. Quanto à importância revelada, 95\% dos indivíduos com alto interesse consideram muito importante a disposição de cobertura arbórea nas cidades.

Ainda vertendo sobre atitudes, aproximadamente $51 \%$ dos entrevistados afirmaram não colaborar de nenhuma forma com a cobertura arbórea urbana do município. A proporção restante executa as ações que vão desde não danificar até a realização de manejo. Nesse sentido, cabe destacar a atuação ativa de cerca de $40 \%$ dos entrevistados plantando ou fazendo manutenção do recurso, em contrapartida, uma maioria agindo quase que passivamente apenas não danificando o mesmo. Observa-se que a falta de um manejo adequado do ativo muitas das vezes influi para que os moradores exerçam atividades de manejo, às quais deveriam ser executadas por pessoal técnico.

As áreas com maior efetividade das ações do poder municipal no que tange ao planejamento e manejo do ativo apresentaram maior sensibilidade ao nível de incômodos decorrente da falta desse recurso. No Plano Diretor Sul a proporção de entrevistados que afirma gerar muito incômodo é igual a $76,47 \%$ e $82,09 \%$ nas regiões Sudoeste e Sudeste, respectivamente. Em contrapartida, nas regiões ao Noroeste e Nordeste do Plano Diretor, esses valores foram $66,44 \%$ e $68,35 \%$, respectivamente.

Ainda quanto a percepções, os principais incômodos indicados decorrentes da falta de elementos arbóreos no recinto urbano foram: maior temperatura, relatada por $60,85 \%$ dos entrevistados, sobretudo nas regiões do Plano Diretor Sul; maior poluição do ar com $19,95 \%$ sendo que as maiores proporções estão nas regiões ao Norte condizendo com maior incidência de ventos sobre o cerrado descoberto dessas regiões; a propagação de problemas de saúde relativa a $16,46 \%$, que também tem maior influência das regiões ao Norte, e maior consumo de energia em torno de 3\%, como dispõe a Tabela 1.

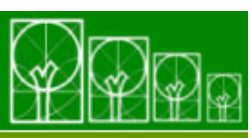

$\mathbf{S} \cdot \mathbf{B} \cdot \mathbf{A} \cdot \mathbf{U}$ Soc. Bras. de Arborização Urbana 
Tabela 1. Principais Incômodos produzidos pelas falta de vegetação arbórea no recinto urbano

Table 1. Main inconveniences due to the lack of vegetation in urban areas

\begin{tabular}{lcccccc}
\hline \multicolumn{1}{c}{ Resposta } & \multicolumn{5}{c}{ Regiões } \\
\cline { 2 - 5 } & $\begin{array}{c}\text { Noroeste } \\
(\%)\end{array}$ & $\begin{array}{c}\text { Nordeste } \\
(\%)\end{array}$ & $\begin{array}{c}\text { Sudoeste } \\
(\%)\end{array}$ & $\begin{array}{c}\text { Sudeste } \\
(\%)\end{array}$ & Total (\%) \\
\hline $\begin{array}{l}\text { Maior consumo de } \\
\text { energia }\end{array}$ & 3,60 & 0,00 & 3,92 & 2,99 & 2,74 \\
$\begin{array}{l}\text { Maior poluição do ar } \\
\text { Maior nível de }\end{array}$ & 20,14 & 23,38 & 17,65 & 18,66 & 19,95 \\
$\begin{array}{l}\text { temperatura } \\
\text { Problemas de saúde }\end{array}$ & 57,55 & 55,84 & 66,67 & 64,93 & 60,85 \\
\hline
\end{tabular}

Com relação às desvantagens apresentadas, a sujeira das ruas e calçadas causada pelos escombros das folhas das árvores e galhos foi a alternativa com maior índice de resposta $(41,46 \%)$, seguida de redução da iluminação pública e problemas com a rede elétrica e/ou telefônica decorrente da má disposição das árvores, ambas com 23,66\%. Em último lugar, os indivíduos afirmam que as rachaduras das calçadas são também uma forma de desvantagens, esta representa $11,22 \%$ dos entrevistados. Porém, caso sejam agrupadas essas três últimas alternativas por se tratar de desvantagens passivas de atenuação caso houvesse um planejamento e manejo adequado, praticamente dois terços das desvantagens problemas apresentados seriam dirimidos. Esses resultados estão transcritos na Tabela 2.

Tabela 2: Principais desvantagens observadas da disposição de vegetação arbórea no recinto urbano.

Table 2: Main disadvantages related to the disposition of woody vegetation in the urban area.

\begin{tabular}{ll}
\hline Desvantagens & $(\%)$ \\
\hline Sujeiras das ruas e calçadas & 41,46 \\
Redução da iluminação pública & 23,66 \\
Problemas com a rede elétrica ou telefônica & 23,66 \\
Rachadura nas calçadas & 11,22 \\
\hline
\end{tabular}

Ainda tratando-se da interação do entrevistado com o meio ambiente, questionou-se quanto à freqüência de visita deste a local que possa ser estabelecido contato com árvores. Os resultados revelam que $72,68 \%$ freqüentam algum tipo de praça, bosque e ou áreas de preservação ambiental em média três vezes por mês. Desse total, cerca de $70 \%$ possuem atitudes consideradas integrativas, $28 \%$ atitudes escapistas e aproximadamente $15 \%$ são considerados ambivalentes. Cabe ressaltar, que apesar de quase um terço dos entrevistados não estabeleça contato direto com essas áreas, $59,8 \%$ concordam que quem

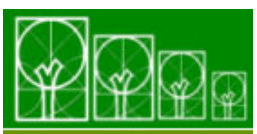


derruba uma árvore na rua deveria pagar indenização à prefeitura e 25\% que se isolam para não compartilhar a destruição de arvores nas ruas da cidade.

Foi levantada a hipótese de que o ideal urbanístico do município baseado em marketing como atrativo turístico, contido no slogan "a capital ecológica", poderia estar impregnado de imprecisões à medida que os seus habitantes não conseguissem refletir essas características em suas avaliações, partindo-se do amplo olhar da cidade, voltando-se para as quadras e depois para própria rua de residência do entrevistado. Nesse aspecto, verificou-se que em relação à avaliação no âmbito da cidade, os que consideram os serviços péssimos, ruins e regulares somam-se $43,42 \%$ enquanto que quando a avaliação é relativa à quadra essa proporção aumenta para $61,47 \%$. Essa estimativa é maior ainda quando o ponto de observação é a rua, somaram $73,61 \%$ dos indivíduos da amostra considerada.

A proporção das pessoas que avaliam como sendo boa a vegetação da cidade na visão macro cai mais da metade quando a avaliação é referente à rua. Infere-se que o entrevistado tende a apresentar claro descontentamento com os serviços dos quais usufrui diretamente, ou que ao menos deveria usufruir, mostrando que a vegetação urbana de Palmas não desempenha de forma adequada seu papel no seu ambiente de convivência, confirmando o argumento apresentado sobre a centralização da cobertura arbórea da cidade.

Resultado análogo foi obtido quando da avaliação por macro regiões. Gradualmente; quando se desloca de uma visão macroscópica da paisagem arbórea da cidade no sentido de uma visão do "habitar", ambiente próximo do entrevistado, por exemplo, a quadra ou rua em que reside; este revela que os serviços da vegetação arbórea do município ainda não estão dispostos em quantidades suficientes. Visualmente, sobretudo nas regiões periféricas, a cidade apresenta grandes áreas sem vegetação arbórea planejada com partes sem qualquer disposição desses elementos servindo como instrumento urbano. Esse fato ocorre ao menos por dois motivos, por falta de uma intervenção da gestão pública, mantendo assim o status quo do cerrado, e devido às intervenções sem planejamento que produzem uma vegetação arbórea raquítica ou inapropriada para as condições físicas e climáticas da região.

A eficiência dos atributos arbóreos fornece uma indicação de quão bem estão sendo fornecidos os ativos arbóreos nas cidades. Aglutinados, esses atributos produzem bemestar e melhor qualidade de vida para o homem citadino. Nesse sentido, o resultado dessa análise para o âmbito micro revela que para a maioria dos entrevistados, o sombreamento é o atributo mais eficiente, com média de 3,3 na escala. Seguido pelo efeito sobre a

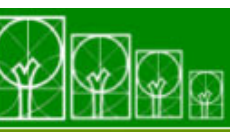

$\mathbf{S} \cdot \mathbf{B} \cdot \mathbf{A} \cdot \mathbf{U}$ Soc. Bras. de Arborização Urbana 
temperatura e ventilação; com nível de eficiência de 2,8 e 2,7; respectivamente. Em quarto, o controle da poluição obteve uma média de 2,6. Os demais obtiveram média igual ou inferior a 2, como mostra a Figura 4. Excetuando o sombreamento, todos os demais atributos apresentaram algum índice de ineficiência. Se de um lado boa parte das características avaliadas não teve uma avaliação significativa, percebe-se que os indivíduos tendem a avaliar melhor os atributos que são sentidos diretamente em face da condição sócio-ambiental no recinto em que este vive.

Figura 4: Avaliação da eficiência da vegetação arbórea de Palmas com base na escala Likert.

Figure 4: Efficiency assessment of the woody vegetation in Palmas based on the Likert scale

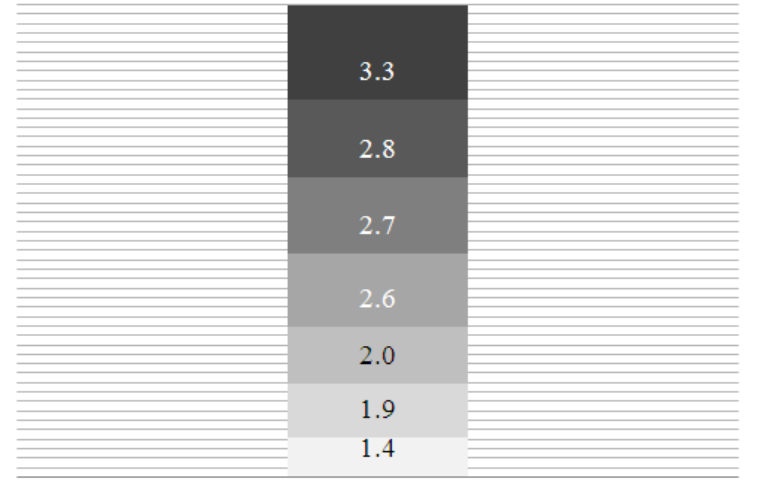

Sem Eficiência 1--2--3--4--5 Muito Eficiente

- Sombreamento
- Temperatura
— Ventilação
— Poluição
- Frutos
- Ruídos
Remédios

Remédios

Quanto à consistência das respostas, especificamente no caso do sombreamento, a despeito de sua avaliação relativamente superior às demais, dos 53,9\% dos entrevistados que expressaram insatisfação com a cobertura arbórea da rua, 57,47\% elegeram como o principal problema a falta de sombreamento. Esse resultado poderia ser um indicativo de inconsistência da avaliação quanto à eficiência caso os mesmos indivíduos estivessem expressando tais comportamentos. Porém ao contrapor os dados, observa-se que próximo de $71,5 \%$ das pessoas insatisfeitas com o serviço arbóreos da rua atribui peso no máximo igual a 3 , ou seja, no máximo estes posicionam-se como indiferentes à questão. $O$ outro extremo revela que $94,18 \%$ dos entrevistados que estão satisfeitos estabelecem peso igual ou superior a 3.

Em suma, o peso atribuído ao sombreamento não o exime de ainda ser o principal problema na rua do entrevistado. Isso é possível já que mesmo sendo o único considerado 
que apresente algum tipo de eficiência sua provisão ainda é aquém do que os indivíduos consideram como necessária. Todavia, deve haver certa cautela a respeito da análise de eficiência para alguns dos atributos, haja vista não se mostrarem significativamente relacionados a outras variáveis. Além dos problemas particulares a atributos, foram declarados outros estigmas arbóreos da rua do entrevistado, os quais estão dispostos na Tabela 3.

Tabela 3: Principais problemas provocados pela cobertura arbórea urbana da rua do entrevistado

Table 3: Main problems caused by the urban tree canopy on the interviewee's street

\begin{tabular}{ll}
\hline Estigmas arbóreos & $(\%)$ \\
\hline Sujeiras das ruas e calçadas & 12,22 \\
Problemas com a rede elétrica e/ou telefônica & 10,41 \\
Pouco sombreamento & 57,47 \\
As raízes provocam prejuízos às calçadas & 6,79 \\
Falta manutenção & 0,45 \\
Falta manejo & 4,07 \\
Tem poucas árvores & 8,6 \\
\hline
\end{tabular}

O apelo ao pouco sombreamento no ambiente residencial retrata bem que a gestão da cidade não se propôs oferecer essencialmente qualidade de vida decorrente da cobertura arbórea e sim com o intuito, sobretudo de compor um ideal urbanístico politicamente correto. A intervenção do governo municipal no sentido de prover árvores no interior das quadras está sendo gradativamente substituída por ações de residentes, sobretudo nas unidades residenciais. Assim, a respeito da presença de árvores ou não no lote do entrevistado; $84,88 \%$ dos indivíduos afirmam ter árvore no lote, uma média de 3,4. Já ao entorno do lote e considerando expressamente a percepção do público entrevistado, obteve-se uma média de 7,76. A despeito de seus benefícios, tais ações podem provocar acidentes quando do manejo, conflitos viários com outros elementos urbanos, sobrepor às desvantagens desse ativo, entre outros.

\section{CONCLUSÕES}

É sabido que as árvores urbanas oferecem inúmeros benefícios para o recinto das cidades. Desde a purificação do ar, melhoria do micro-clima, redução da incidência de raios solares, redução da velocidade do vento, equilíbrio das cadeias alimentares e diminuição de

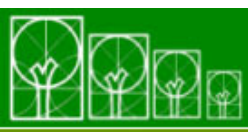

S · B · A · U Soc. Bras. de Arborização Urbana 
pragas e agentes vetores de doenças, amortecimento de ruído até ação sobre o bem estar físico e psíquico do homem, entre outros. Tais benefícios se tornam preciosos quando a recinto urbano em questão apresenta aspectos físicos e climáticos como o da cidade de Palmas - TO.

A despeito do potencial urbanístico da mais jovem capital da federação, sua cobertura arbórea tem sido tema de discussões entre pesquisadores e gestores, sobretudo no que tange à quantidade e a qualidade da mesma. Tal panorama ora refletido nas atitudes e percepções de seus residentes propõe uma contribuição para a compreensão de seus elementos constitutivos bem como dos prejuízos que a sua má disposição propõe. Nesse sentido, dever-se-ia esperar que quanto maior o grau de percepção da população, mais esta seria um elemento atuante na promoção do ativo.

No que tange a percepção, aspectos como nível de interesse por questões ambientais e nível de importância dada ao ativo para o planejamento urbano revelaram relativo apreço por parte do entrevistado. Os resultados favoráveis para ambos os requisitos que por sinal foi característico da amostra é minimizado quando o assunto é atuar ativamente em ações que produzam resultados para a coletividade, que vão desde o próprio plantio de árvores até o seu manejo. Na prática essa vertente se confirma haja vista que a grande maioria da população prefere esperar pela ação do poder público municipal, recebendo em troca relativa redução da qualidade de vida no município. Tais estigmas são vistos no nível de incômodo percebido pelos entrevistados, em especial maiores níveis de temperatura.

Foi evidenciado que a percepção de uma cidade ecologicamente correta ainda pode ser conferida na visão macro. O uso do referido slogan bem como da vegetação arbórea das vias centrais da cidade muito das vezes assumiu o papel de promover uma ideologia político-partidária em detrimento das reais funções que deveria exercer o ativo em questão. É tão verdade que no âmbito da rua do entrevistado a avaliação da qualidade dos serviços das árvores urbanas cai significativamente.

O claro descontentamento com os serviços dos quais usufrui diretamente, ou que ao menos deveria usufruir, remontam para uma real imprecisão das políticas públicas para o setor, além de enfatizar a centralidade dos mesmos. Concomitantemente, a avaliação dos principais serviços oferecidos pela cobertura arbórea da urbe revelou relativa escassez de eficiência, apenas o sombreamento com algum nível. Mesmo que isso não o exime de ainda ser o principal problema na rua do entrevistado.

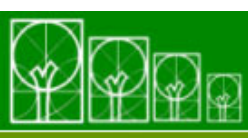

$\mathbf{S} \cdot \mathbf{B} \cdot \mathbf{A} \cdot \mathbf{U}$ Soc. Bras. de Arborização Urbana 
No que tange às atitudes, a significativa proporção de indivíduos integrativos em relação aos demais revela em escala de grandeza a escolha social quanto à necessidade de disposição de árvores no recinto da cidade. Entrevistados integrativos são em sua maioria os indivíduos que executam ações como plantar árvores e manejo das mesmas. Notadamente, o alto índice de radiação solar, os fortes ventos, as baixas na umidade relativa do ar bem como a passividade do poder público são os principais fatores que contribuem para que a população atue dessa maneira.

Partindo-se do panorama atual da vegetação arbórea além de considerar a infraestrutura urbana que a cidade dispõe para a ampliação da oferta desses serviços poder-se-ia considerar que não são raras as alternativas para se contornar os graves problemas que a cidade enfrenta. Porém ainda é possível presenciar ação dos gestores municipais implantando uma vegetação arbórea que presa muito mais pela estética do que pela funcionalidade, em geral com o uso de espécies aclimatadas de outras regiões acompanhadas de um manejo simbólico. Nesse aspecto as percepções e ações da população residente têm sido muito mais em decorrência desse cenário do que uma prática cultural.

\section{REFERÊNCIAS}

ALVES, S. M; GOUVEIA, V. V. Atitude em Relação à Arborização Urbana: uma contribuição da psicologia ambiental para a qualidade de vida urbana. Textos do Laboratório de Psicologia Ambiental. v. 4, n. 6, p.1-6, 1995.

BERTONE, L. F.; MELLO, N. A de. PALMAS: Perfil Ambiental e Gestão Urbana Convergem para a Sustentabilidade Ambiental? Mercator: Revista de Geografia da UFC. Ano 03, n. 06, p.71-88, 2004.

BRASIL, República Federativa. Constituição Federal de 05 de outubro de 1988.

COSTA, R. Geniany Silva; COLESANTI, Marlene Muno. A Contribuição da Percepção Ambiental nos Estudos das Áreas Verdes. O Espaço Geográfico em Análise. 22, p. 238$251,2011$.

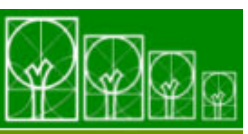

$\mathbf{S} \cdot \mathbf{B} \cdot \mathbf{A} \cdot \mathbf{U}$ Soc. Bras. de Arborização Urbana 
ELEJABARRIETA, F. J; INIGUEZ, L. Construccion de Escalas de Actitud Tipo Thurst y Likert. U.A.B 47p. 1984. Disponível em: <http://www.pdf-search-engine.com/likert-escalapdf.html>. Acesso em: 14 de fevereiro de 2010.

FAGGIONATO, S. Percepção Ambiental. Disponível em <http://educar.sc.usp.br/biologia/textos/m_a_txt4.html> Acesso em 08 de ago. 2011.

FERREIRA, I. M.. Bioma Cerrado: caracterização do subsistema de Vereda. Observatório Geográfico de Goiás. v. 1, p. 1-13, 2005.

FIGHERA, D. da R. A Efetividade do Projeto de Cidade Ecológica de Palmas (TO) pelos seus Espaços Verdes. Dissertação (Mestrado) - Universidade Federal do Tocantins. Curso de Pós-Graduação em Ciências do Ambiente. Palmas, 187p. 2005.

GOLD, S. M. Social Benefits of Trees in Urban Environments. International Journal of Environment Studies, v. 10, p. 85-90, 1977.

GREY, G. W; DENEKE, F. J. Urban forestry. New York: Jhon Wiley, 1978. 279 p.

LIRA, E. R. A gênese de Palmas - Tocantins. Programa de Pós-Graduação em Geografia. Universidade Estadual Paulista. Dissertação (Mestrado). Presidente Prudente,1995. 296p.

MASCARÓ, L; MASCARÓ, J. Vegetação Urbana. 2 ed. Porto Alegre: Mais Quatro, 2005. 204p.

MELAZO, G. Coelho. Percepção Ambiental e Educação Ambiental: uma reflexão sobre as relações interpessoais e ambientais no espaço urbano. Olhares \& Trilhas. Uberlândia, Ano VI, n. 6, p. 45-51, 2005.

MILANO, M.S; DALCIN, E.C. Arborização de vias públicas. Rio de Janeiro. RJ: Light, 2000. 226p.

NASCIMENTO JÚNIOR, B; Conhecendo o Tocantins: História e Geografia. 4 ed. Goiânia : Gráfica editora, 2006. 139p.

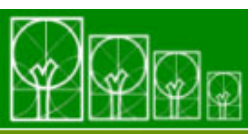


PALMAS. Caderno de Revisão do Plano Diretor. Prefeitura Municipal de Palmas, 2002.

Plano Diretor Participativo de Desenvolvimento Territorial: relatório da leitura técnica e comunitária - meio ambiente. Prefeitura de Palmas, 2006.

. Disponível em: <www.palmas.to.gov.br>. Acessado em: 31 ago. 2009.

SEPLAN - Secretaria do Planejamento e Meio Ambiente do Tocantins. Plano das bacias hidrográficas do entorno de Palmas - TO. 2004. Disponível em: <www.seplan.to.gov.br>. Acesso em: 21 ago. 2009.

UNITINS - Fundação Universidade do Tocantins. Disponível em:

<http://www3.unitins.br/portal/>. Acesso em: 25 de fevereiro 2010.

VASCONCELLOS, R. B de Hollanda. A Sintaxe Espacial como Instrumentos de Análise da Dualidade Mórfica de Palmas. Programa de Pós-graduação da Universidade de Brasília. (Dissertação Mestrado). FAU/UnB, 2006. 170p.

WOLF, K. L. PhD. What Could We Lose? economic values of urban forest benefits. In: 6th Canadian Urban Forest Conference. Anais... Kelowna. B.C. October, 2004. p. 19 -23.

XAVIER, F. O. R. Palmas: uma capital para todos? Programa de Pós-Graduação em Geografia. (Dissertação Mestrado), Universidade Federal do Paraná, 131p. 2007. 